\title{
Critical assessment of high-circulation print newspaper coverage of the Institute of Medicine report Dietary Reference Intakes for Calcium and Vitamin D
}

\author{
Daniel P Hatfield ${ }^{1,2}$, Kathryn P Sweeney ${ }^{1}$, Joseph Lau ${ }^{1,2}$ and Alice H Lichtenstein ${ }^{1,2,3, *}$ \\ 'Gerald J. and Dorothy R. Friedman School of Nutrition Science and Policy, Tufts University, 150 Harrison \\ Avenue, Boston, MA 02111 , USA: ${ }^{2}$ Center for Clinical Evidence Synthesis, Institute for Clinical Research and \\ Health Policy Studies, Tufts Medical Center, Boston, MA, USA: ${ }^{3}$ Cardiovascular Nutrition Laboratory, Jean \\ Mayer-US Department of Agriculture Human Nutrition Research Center on Aging at Tufts University, Boston, \\ MA, USA
}

Submitted 21 November 2012: Final revision received 1 May 2013: Accepted 12 June 2013: First published online 1 August 2013

\begin{abstract}
Objective: To evaluate high-circulation US and Canadian newspaper coverage of the Institute of Medicine (IOM) report Dietary Reference Intakes for Calcium and Vitamin D and assess pre-report and post-report reporter-specific vitamin D-related coverage.

Design: Two independent reviewers analysed the newspaper articles. The key report findings cited, proportion of sentences describing the IOM report and proportion of sentences describing critical viewpoints on the report were calculated. The content of articles written by reporters with a history of pre-report vitamin D-related articles was compared with that of articles written by reporters without such a history.

Setting: Factiva and LexisNexis searches of the top thirty US and three Englishlanguage Canadian print newspapers, by circulation.

Subjects: Articles on the IOM report published from 30 November to 21 December 2010 and previous vitamin D-related articles written by the same reporters.

Results: Only ten articles met inclusion/exclusion criteria. Articles inconsistently cited the key findings in the IOM report. Reporters with a history of pre-report articles highlighting the benefits of vitamin $\mathrm{D}$ dedicated a greater proportion of sentences to viewpoints critical of the IOM report $(P<0 \cdot 01)$. There was no significant difference between pre-report publication history and proportion of sentences focused on the IOM report. A borderline-significant difference $(P=0.058)$ was observed between pre-report articles highlighting the benefits of vitamin $\mathrm{D}$ and the absence of reference to potential risks of vitamin $\mathrm{D}$ overconsumption.

Conclusion: Our findings suggest that newspaper articles did not consistently or comprehensively report the IOM recommendations and that pre-report publication history of reporters was related to post-report article content.
\end{abstract}

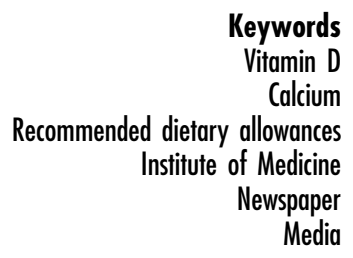

Mass media play a key role in informing the general public of scientific developments. The most recent account identified, a 2005 Kaiser Family Foundation survey, reported that $40 \%$ of respondents indicated they get health information mainly from the media; in comparison, $20 \%$ reported getting health information mainly from health professionals and $14 \%$ from family members and friends ${ }^{(1)}$. Health information reported in the media has been shown to influence individual behaviours ${ }^{(2,3)}$. While in recent years top print newspapers' circulation has waned, largely giving way to Internet and other electronic media, print newspapers continue to play a primary role in public health agenda-setting and provide the base content for many other forms of media ${ }^{(4)}$.

Concern has been raised that some mainstream science reporting aimed at the general public includes inaccuracies ${ }^{(5,6)}$ or other shortcomings, such as incompleteness, hype or bias ${ }^{(7)}$. In one review of over 500 healthrelated stories, satisfactory ratings were given to just 33\% of stories for quantifying harms, $35 \%$ for discussing the quality of the evidence, and $56 \%$ for seeking independent sources and exploring conflicts of interest ${ }^{(8)}$.

Some research suggests that media reports on nutrition topics are not comprehensive or balanced. For example, 
one analysis of thirty-nine nutrition articles in British tabloids found that most articles did not contextualize research findings or provide accurate, balanced information $^{(9)}$. Another analysis of US media coverage of the 1995 Dietary Guidelines for Americans found that the popular press focused on some individual guidelines more than others: guidelines around alcohol, exercise, vegetarian diets and weight gain were widely reported, whereas dietary fibre was seldom discussed ${ }^{(10)}$. The authors hypothesized that the media emphasized these particular guidelines because they were unusual, reflected a change or were perceived as interesting or otherwise newsworthy by their readership. No other recent reports analysing newspaper coverage of US government dietary guidance were identified in the peer-reviewed literature.

In the 2000s growing scientific attention to vitamin D sparked increasing public interest in the nutrient. A MEDLINE search for articles with 'vitamin D' in the title yielded 3957 studies published from 2006 to 2010, more than double the number of studies (1986) published in the prior 5-year period. This increase in the volume of scientific publications in the area of vitamin $\mathrm{D}$ was mirrored by a rise in vitamin D-related coverage in the popular press. A Factiva search for 'vitamin D' in top US and Canadian newspapers yielded 3519 articles from 2006 to 2010, more than double the 1531 articles for 2001 to 2005. Many of these articles suggested, implicitly or explicitly, that vitamin D deficiency is widespread, that deficiency causes extra-skeletal health risks, or that intakes above recommended levels yielded health benefits for the general population.

The influence of increased reporting may have contributed to the marked changes in clinical practice and consumer behaviour during these same years. In its 2009 annual report, Quest Diagnostics reported a more than $50 \%$ increase in year-over-year revenues from vitamin D testing ${ }^{(11)}$. According to Nutrition Business Journal data cited in the Wall Street Journal, sales of vitamin D supplements also increased more than tenfold during the 2000s, reaching \$US 425 million in 2009, compared with \$US 40 million in $2001^{(12)}$.

New scientific evidence, especially with regard to vitamin $\mathrm{D}$, triggered the Institute of Medicine (IOM; sponsored jointly by the US and Canadian governments) to reassess its vitamin $\mathrm{D}$ and calcium recommendations released in $1997^{(13)}$. The resulting IOM report, Dietary Reference Intakes for Calcium and Vitamin D, released in November 2010 and published in 2011, suggested that the recent changes in clinical and consumer practice might not be fully supported by available evidence. For example, it noted that, while certain sub-populations may be at risk of deficiency, 'a majority of the population is meeting its needs for vitamin $\mathrm{D}^{,(14)}$. Additionally, the authors of the IOM report noted concerns regarding potential adverse effects associated with vitamin $\mathrm{D}$ intakes exceeding $100 \mu \mathrm{g} / \mathrm{d}(4000 \mathrm{IU} / \mathrm{d})^{(15)}$. Subsequent publications by the
IOM panel members have expanded on some of these points ${ }^{(16-19)}$. Given the divide between the IOM recommendations and mainstream trends, we undertook a systematic analysis of the comprehensiveness and balance of newspaper coverage of the IOM report.

The present study examined print newspaper coverage of the IOM's report, with specific emphasis on vitamin $\mathrm{D}^{(15)}$. The scope of this project was limited to vitamin D because of the perceived controversy sparked by the release of the report, which drew support from some experts in the field ${ }^{(20,21)}$ and criticism from others, who contended that updated IOM Dietary Reference Intake values for vitamin D were too low ${ }^{(22,23)}$. Our aims were to determine the frequency with which the report's key findings were cited; to evaluate the proportion of sentences focused on the IOM report and critical of the report; and to assess whether the content of articles written by reporters with a history of pre-report vitamin D-related articles differed from that of articles written by reporters without such a history.

\section{Methods}

\section{Newspaper selection}

The Dow Jones Factiva electronic database was searched to retrieve newspaper articles focused on the IOM report and its findings related to vitamin D. This search included articles published in the top thirty US print newspapers and the top three English-language Canadian newspapers, defined by circulation data ${ }^{(24,25)}$. The distribution between English-language Canadian and US newspapers included was determined by relative population: Canada's population is approximately one-tenth that of the USA. In addition, all other English-language Canadian newspapers have average daily circulations lower than 150000 and therefore lack the reach of US publications included in the search. Internet publications, magazines, television news or other media outlets, which employ a range of journalistic practices that would introduce excessive heterogeneity into the sample, were excluded.

\section{Search terms and inclusion/exclusion criteria}

The search included the three-week period immediately after the news embargo was lifted, from 30 November 2010 to 21 December 2010. That period of time was deemed adequate to capture immediate news coverage and coverage in weekly science and health sections of the newspapers. The search term was 'vitamin D and (Institute of Medicine or IOM)'. We excluded articles that were exact duplicates; opinion, editorial and interview question-and-answer pieces; and letters to the editor. No criteria were identified in the literature for designating a newspaper article as having a specific topic focus. To standardize our criteria, a priori we set a minimum of five mentions of the term 'vitamin D' as an indicator that articles focused principally on the subject. 
Also excluded were articles shorter than 500 words or longer than 1500 words (excluding graphics and sidebars), so as to exclude news briefs or extended feature articles. If a reporter wrote more than one article meeting inclusion/exclusion criteria, the later article(s) were excluded to avoid bias that might be associated with a second article on the IOM report and also to avoid duplicate representation of individual reporters in our analysis of publication histories. The search was repeated using the LexisNexis database to confirm that all articles meeting the search parameters were captured.

\section{Coding newspaper article content}

The report brief issued by the IOM was used to identify key conclusions from the full report ${ }^{(14)}$, and previously published criteria for the evaluation of health journalism were used to develop our extraction form ${ }^{(9,26-28)}$. The form included a list of thirteen specific findings, which was used to evaluate the comprehensiveness of each newspaper article. These findings included: (i) the former Adequate Intake for the general population $(5 \mu \mathrm{g} / \mathrm{d}$ (200 IU/d)); (ii) the IOM's updated RDA for the general population $(15 \mu \mathrm{g} / \mathrm{d}(600 \mathrm{IU} / \mathrm{d}))$; (iii) the increased dietary vitamin $\mathrm{D}$ requirements for adults over 70 years; (iv) the upper level of $100 \mu \mathrm{g} / \mathrm{d}(4000 \mathrm{IU} / \mathrm{d})$, beyond which health risks increase; (v) risks to the kidney and heart associated with excessive vitamin D intakes; (vi) the IOM's review of available scientific literature and its findings that (vii) bone/skeletal health is the only outcome for which sufficient evidence exists to make recommendations, (viii) there are limitations to research on the association between health conditions other than bone health and vitamin D status and (ix) most Americans' and Canadians' vitamin D levels are sufficient; (x) the IOM's inclusion of calcium in the report; the amount of vitamin D that can be commonly found in each (xi) food and (xii) dietary supplements; and (xiii) factors (such as skin pigmentation) that might affect vitamin D status. Each article was reviewed by two authors (K.P.S. and D.P.H.) and coded 'yes' or 'no' for each finding. Data were reviewed and discrepancies resolved by consensus. A third party (A.H.L.) was designated to reconcile points where consensus could not be reached, but such arbitration was not needed.

Additional information was extracted in the following categories: (i) 'IOM', i.e. the number of sentences referring principally to the IOM's findings or directly quoting a member of the IOM committee; (ii) 'criticism', i.e. the number of sentences referring principally to opinions of an individual or organization critical of the IOM's research process or its findings, or presenting a point of view that runs directly counter to the IOM findings; (iii) 'neutral', i.e. the number of sentences referring principally to factual information about vitamin $\mathrm{D}$, the vitamin $\mathrm{D}$ supplement industry, scientific studies, or an individual or group expressing an impartial stance on the IOM report; and (iv) 'non-vitamin D', i.e. the number of sentences referring principally to topics not directly relevant to vitamin D or the IOM's findings with regard to this nutrient (e.g. sentences focused on calcium). The grammatical structures of all sentences, including the grammatical subjects of main clauses, were mapped and used to guide the coding process. The following sentence is an example: 'the IOM report cautioned that getting excessive vitamin D can damage the kidneys and heart' ${ }^{(29)}$. Here, the grammatical subject of the main clause is 'report' and the sentence was therefore coded 'IOM'. In some cases, grammatical subjects did not accurately reflect sentences' primary foci. These discrepancies were resolved by consensus. The following sentence is an example: 'the recommendations left many proponents of higher vitamin D intakes bitterly disappointed' ${ }^{\text {(30) }}$. Here, the grammatical subject is 'recommendations', but given that the sentence focuses on critical viewpoints towards the IOM report, the sentence was coded 'criticism'. Other special cases, such as compound sentences (i.e. multiple main clauses) and sentence fragments (i.e. no main clauses), were also resolved by consensus. All coding was unanimous.

\section{Analysis of reporters' publication bistories}

Each article meeting the inclusion/exclusion criteria was assessed for whether the reporter had previously written a newspaper article on vitamin D during the 5-year period before the IOM report was released (30 November 2005 to 29 November 2010). The Factiva and LexisNexis databases were searched, including the top thirty US and top three Canadian newspapers, using '(reporter's last name) and vitamin D' as keywords.

From these results, articles on vitamin $\mathrm{D}$ benefits were identified. An article was categorized as addressing vitamin D benefits if it contained at least 500 words (excluding graphics and sidebars), had at least five references to 'vitamin D' and had at least one of the following elements: discussion of research suggesting that deficiency causes health risks in areas other than bone health; discussion of research suggesting that deficiency is widespread within the US and/or Canadian populations; or discussion of research suggesting that there are health benefits to taking vitamin $\mathrm{D}$ at levels that exceed the Dietary Reference Intake. The IOM report indicated, based on the committee's review of the available data, that available evidence does not conclusively support these concerns.

\section{Analysis}

The percentage of articles reporting each of the thirteen coded findings was recorded. For each article, the total number of sentences pertaining to vitamin $\mathrm{D}$ was recorded (total sentences, minus sentences coded as 'non-vitamin D'). The quantity of sentences coded in each category ('IOM', 'criticism', 'neutral') was calculated as a proportion of the total number of sentences pertaining to vitamin D.
} 
Articles covering the IOM report were grouped into two categories: (i) those written by reporters whose prereport publication history included articles on vitamin D benefits; and (ii) those written by reporters with no such articles. For each group, the mean proportion of sentences coded 'IOM' was calculated and Student's $t$ test was used to test for statistically significant differences between means. This process was then repeated for the mean proportion of sentences coded 'criticism'. Pearson's $\chi^{2}$ test was used to determine whether reporters' vitamin D publication history was significantly associated with articles' inclusion of the 'risk of kidney or heart damage with excess vitamin D' finding. All data are reported as means and standard deviations. A $P$ value of 0.05 was considered statistically significant for all tests. The statistical software package Stata11 was used for statistical analyses.

\section{Results}

\section{Newspaper article selection}

The initial Factiva search yielded twenty articles on the basis of our search terms and the LexisNexis search identified two additional articles (Fig. 1). We excluded eight articles that were exact duplicates; opinion, editorial or interview question-and-answer pieces; letters; or articles shorter than 500 words (excluding graphics and sidebars). Two articles were excluded based on their use of the 'vitamin D' term fewer than five times. Our review of these articles confirmed that they were not principally focused on the IOM report. No additional articles were identified that exceeded the predetermined 1500-word limit. Expanding the search from three to six weeks did not yield additional articles. Likewise, omitting the phrase 'Institute of Medicine' or 'IOM' from the search did not yield additional news articles focused on the release of the report. Two reporters had written two separate articles meeting our search parameters. Consistent with our a priori criteria, the later of the two articles was excluded. One of these excluded articles was similar to the prior article by the same author, with each including nine of the thirteen key findings in our extraction form; the other excluded article was focused mainly on reactions of various interest groups to the report and it included fewer of the thirteen key findings than did the author's prior article (five $v$. nine). Ten articles remained that met the inclusion/exclusion criteria (Fig. 1). The majority of newspapers searched (73\%) provided no

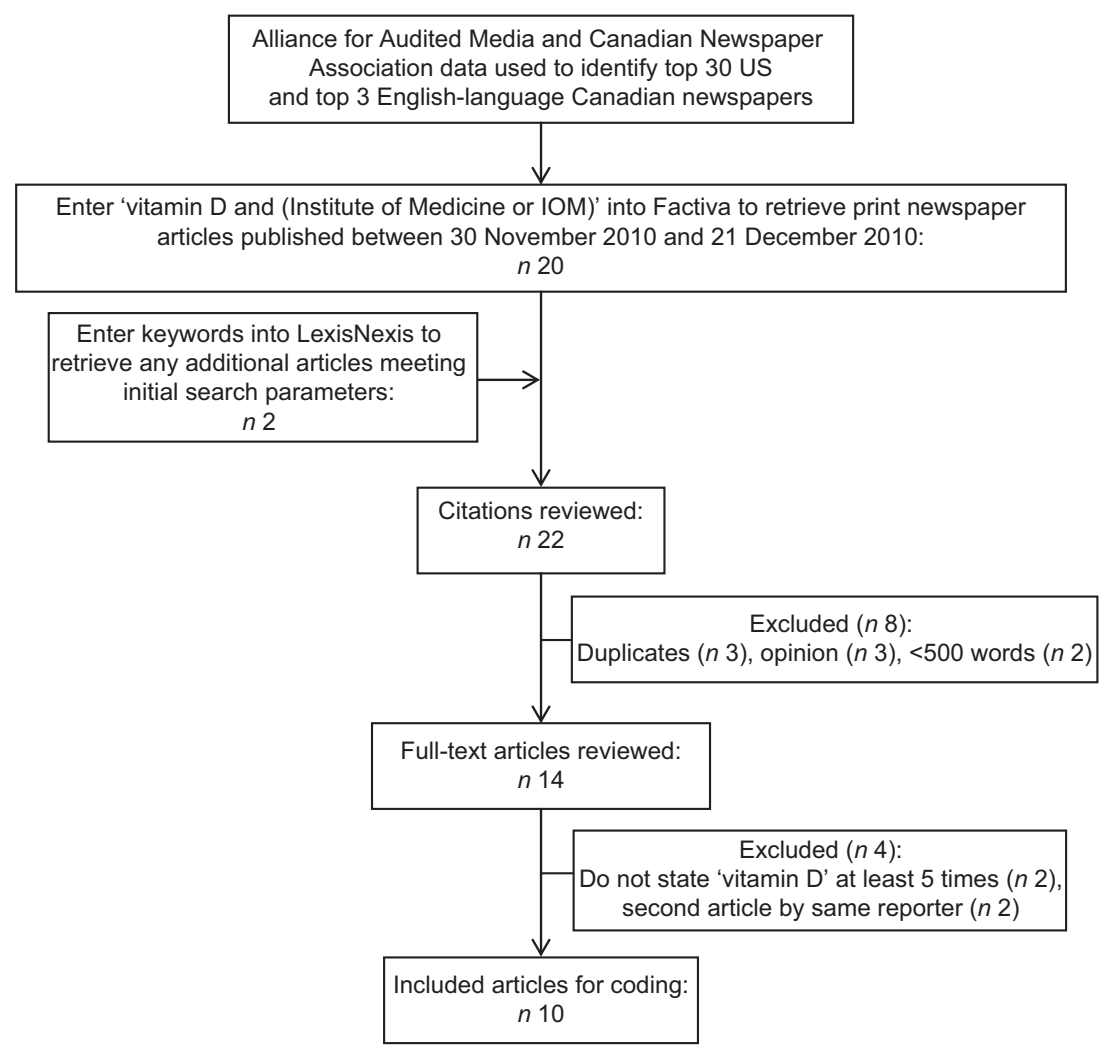

Fig. 1 Selection process to obtain newspaper articles on the Institute of Medicine report Dietary Reference Intakes for Calcium and Vitamin $D$ 
news coverage that met the inclusion/exclusion criteria. Those newspapers that did provide coverage tended to have larger circulations: each of the top four US newspapers, as well as the top two Canadian newspapers, published articles included in our sample.

Characteristics of the included articles are summarized in Table 1 ( $n$ 10). Six of ten articles were published on the date that the Dietary Reference Intakes for Calcium and Vitamin D news embargo was lifted, 30 November 2010. The newspaper sections where the articles appeared varied among publications, and included News, Life, Business and Living Arts. One newspaper, The Boston Globe, published two articles written by different reporters that met our inclusion/exclusion criteria. The number of words per article ranged from 539 to 1290 (mean 924 (SD 240)) and the number of sentences per article ranged from 24 to 66 (mean 35 (SD 13.4)).

\section{Newspaper article content}

The proportion of articles including each specific finding, as well as the distribution of sentence types, is summarized in Table 2. All articles reported the new RDA of $15 \mu \mathrm{g} / \mathrm{d}$ $(600 \mathrm{IU} / \mathrm{d})$ for the general population, the inclusion of calcium as well as vitamin D as part of the IOM report, and the limited research on vitamin D and health outcomes other than bone health.

The percentage of articles citing additional IOM report findings varied considerably. More than half of the articles reported the following: an increased RDA for individuals over 70 years old; the upper level of $100 \mu \mathrm{g} / \mathrm{d}$ ( $4000 \mathrm{IU} / \mathrm{d}$ ); one or more factors that may increase the risk of low vitamin D status; that most Americans/Canadians have sufficient serum vitamin D levels; that bone health is the only outcome conclusively associated with vitamin D status; and that the IOM systematically reviewed the available peer-reviewed literature. Every article mentioned at least two extra-skeletal health issues whose relationships with vitamin $\mathrm{D}$ were addressed in the report. The most commonly mentioned outcomes included cancer $(100 \%$ of articles), heart disease ( $90 \%$ ), diabetes ( $80 \%$ ), autoimmune disorders $(50 \%)$ and depression (40\%). Half or fewer articles reported the risks to kidney and/or heart health associated with excessive vitamin D intake, the amount of vitamin $\mathrm{D}$ in at least one food source and the amount of vitamin D commonly available in dietary supplements. The proportion of sentences coded as 'IOM' ranged from $26 \%$ to $54 \%$ (mean 42 (SD 8) \%), the proportion of sentences coded as 'criticism' ranged from $4 \%$ to $35 \%$ (mean 18 (sD 11) \%) and the proportion of sentences coded as 'neutral' ranged from $24 \%$ to $69 \%$ (mean 40 (sD 16) \%; Table 2).

\section{Reporters' pre-report articles on vitamin D}

Half of the reporters included in our sample had previously written at least one article meeting our inclusion criteria. These reporters included a significantly higher proportion of sentences critical of the IOM report than

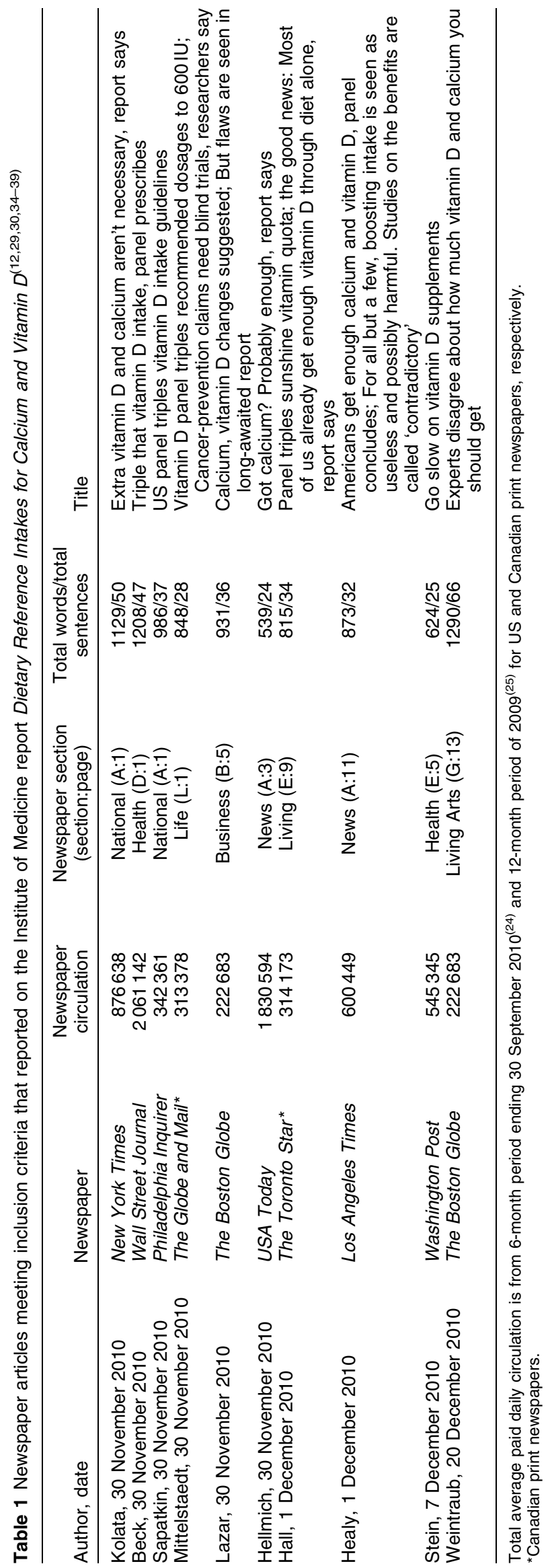


Table 2 Findings included and distribution of sentence types in articles covering the release of the Institute of Medicine (IOM) report Dietary Reference Intakes for Calcium and Vitamin $D$ ( $n$ 10)

\begin{tabular}{|c|c|c|c|c|c|c|c|c|c|c|c|}
\hline Specific finding from IOM report & $\begin{array}{l}\text { Kolata } \\
(2010)\end{array}$ & $\begin{array}{l}\text { Beck } \\
(2010)\end{array}$ & $\begin{array}{l}\text { Sapat. } \\
(2010)\end{array}$ & $\begin{array}{l}\text { Mittel. } \\
(2010)\end{array}$ & $\begin{array}{l}\text { Lazar } \\
(2010)\end{array}$ & $\begin{array}{l}\text { Hellm. } \\
(2010)\end{array}$ & $\begin{array}{l}\text { Hall } \\
(2011)\end{array}$ & $\begin{array}{l}\text { Healy } \\
(2010)\end{array}$ & $\begin{array}{l}\text { Stein } \\
(2010)\end{array}$ & $\begin{array}{l}\text { Weint. } \\
(2010)\end{array}$ & $\begin{array}{l}\% \text { including } \\
\text { the finding }\end{array}$ \\
\hline $\begin{array}{l}\text { 1. Previous intake recommendation for general population } \\
(5 \mu \mathrm{g} / \mathrm{d}(200 \mathrm{IU} / \mathrm{d}))\end{array}$ & $\mathrm{N}$ & $\mathrm{Y}$ & $\mathrm{Y}$ & $\mathrm{Y}$ & $\mathrm{Y}$ & $\mathrm{N}$ & $\mathrm{N}$ & $\mathrm{Y}$ & $\mathrm{Y}$ & $\mathrm{N}$ & 60 \\
\hline $\begin{array}{l}\text { 2. New intake recommendation for general population } \\
(15 \mu \mathrm{g} / \mathrm{d}(600 \mathrm{lU} / \mathrm{d}))\end{array}$ & $\mathrm{Y}$ & $\mathrm{Y}$ & $\mathrm{Y}$ & $\mathrm{Y}$ & $\mathrm{Y}$ & $\mathrm{Y}$ & $\mathrm{Y}$ & $\mathrm{Y}$ & $\mathrm{Y}$ & $\mathrm{Y}$ & 100 \\
\hline 3. Increased requirement for people $>70$ years & $\mathrm{N}$ & $\mathrm{Y}$ & $\mathrm{N}$ & $\mathrm{Y}$ & $\mathrm{Y}$ & Y & $\mathrm{Y}$ & $\mathrm{Y}$ & $\mathrm{Y}$ & $\mathrm{Y}$ & 80 \\
\hline 4. Upper level $(100 \mu \mathrm{g} / \mathrm{d}(4000 \mathrm{IU} / \mathrm{d}))$ & $\mathrm{N}$ & $\mathrm{Y}$ & $\mathrm{N}$ & $\mathrm{Y}$ & $\mathrm{N}$ & $\mathrm{Y}$ & $\mathrm{Y}$ & Y & $\mathrm{Y}$ & $\mathrm{Y}$ & 70 \\
\hline 5. Risk of kidney or heart damage with excess vitamin $D$ & $\mathrm{~N}$ & $\mathrm{Y}$ & $\mathrm{N}$ & $\mathrm{N}$ & $\mathrm{N}$ & Y & $\mathrm{Y}$ & Y & $\mathrm{N}$ & $\mathrm{Y}$ & 50 \\
\hline $\begin{array}{l}\text { 6. IOM's research process (review of available scientific } \\
\text { literature) }\end{array}$ & Y & Y & $\mathrm{N}$ & $\mathrm{Y}$ & $\mathrm{Y}$ & $\mathrm{Y}$ & $\mathrm{Y}$ & Y & $\mathrm{Y}$ & $\mathrm{Y}$ & 90 \\
\hline 7. Bone health as only outcome with conclusive evidence & $\mathrm{Y}$ & $\mathrm{Y}$ & $\mathrm{Y}$ & $\mathrm{Y}$ & $\mathrm{Y}$ & $\mathrm{N}$ & $\mathrm{N}$ & $\mathrm{Y}$ & $\mathrm{Y}$ & $\mathrm{Y}$ & 80 \\
\hline $\begin{array}{l}\text { 8. Limitations to research on vitamin D and other health } \\
\text { outcomes }\end{array}$ & $\mathrm{Y}$ & $\mathrm{Y}$ & $\mathrm{Y}$ & $\mathrm{Y}$ & $\mathrm{Y}$ & $\mathrm{Y}$ & $\mathrm{Y}$ & $\mathrm{Y}$ & $\mathrm{Y}$ & $\mathrm{Y}$ & 100 \\
\hline 9. Vitamin D sufficiency among most Americans/Canadians & $\mathrm{Y}$ & $\mathrm{Y}$ & $\mathrm{Y}$ & $\mathrm{N}$ & $\mathrm{Y}$ & $\mathrm{Y}$ & $\mathrm{Y}$ & $\mathrm{Y}$ & $\mathrm{Y}$ & $\mathrm{Y}$ & 90 \\
\hline 10. Inclusion of calcium in IOM report & $\mathrm{Y}$ & $\mathrm{Y}$ & $\mathrm{Y}$ & $\mathrm{Y}$ & $\mathrm{Y}$ & $\mathrm{Y}$ & $\mathrm{Y}$ & $\mathrm{Y}$ & $\mathrm{Y}$ & $\mathrm{Y}$ & 100 \\
\hline 11. Food source(s) of vitamin D, including IU/serving & $\mathrm{N}$ & $\mathrm{Y}$ & $\mathrm{N}$ & $\mathrm{Y}$ & $\mathrm{N}$ & $\mathrm{N}$ & $\mathrm{N}$ & $\mathrm{N}$ & $\mathrm{N}$ & $\mathrm{Y}$ & 30 \\
\hline 12. IU of vitamin D commonly available in dietary supplements & $\mathrm{Y}$ & $\mathrm{N}$ & $\mathrm{Y}$ & $\mathrm{N}$ & $\mathrm{N}$ & $\mathrm{N}$ & $\mathrm{N}$ & $\mathrm{Y}$ & $\mathrm{N}$ & $\mathrm{N}$ & 30 \\
\hline 13. Factor(s) that may increase risk of low vitamin D status & $\mathrm{N}$ & $\mathrm{Y}$ & $\mathrm{Y}$ & $\mathrm{N}$ & $\mathrm{N}$ & $\mathrm{Y}$ & $\mathrm{Y}$ & $\mathrm{N}$ & $\mathrm{Y}$ & $\mathrm{Y}$ & 60 \\
\hline Sentence type (main focus of sentence) & \multicolumn{10}{|c|}{ Proportion of total sentences* } & $\begin{array}{l}\text { Average } \\
\text { proportion }\end{array}$ \\
\hline IOM's research process or findings ('IOM') & 0.42 & $0 \cdot 36$ & $0 \cdot 34$ & 0.43 & 0.45 & $0 \cdot 52$ & $0 \cdot 38$ & 0.54 & $0 \cdot 48$ & $0 \cdot 26$ & 0.42 \\
\hline Statements critical of the IOM or findings ('criticism') & 0.04 & 0.35 & $0 \cdot 17$ & $0 \cdot 25$ & 0.31 & $0 \cdot 22$ & 0.06 & $0 \cdot 14$ & $0 \cdot 24$ & 0.05 & $0 \cdot 18$ \\
\hline Other, neutral vitamin D sentences ('neutral') & 0.53 & $0 \cdot 29$ & 0.49 & 0.32 & $0 \cdot 24$ & $0 \cdot 26$ & 0.56 & $0 \cdot 32$ & $0 \cdot 28$ & 0.69 & $0 \cdot 40$ \\
\hline History of pre-IOM-report vitamin D articles & $\mathrm{N}$ & $\mathrm{Y}$ & $\mathrm{Y}$ & $\mathrm{Y}$ & $\mathrm{Y}$ & $\mathrm{N}$ & $\mathrm{N}$ & $\mathrm{N}$ & $\mathrm{Y}$ & $\mathrm{N}$ & \\
\hline
\end{tabular}

“Non-vitamin D' sentences excluded from the denominator in calculating the proportion of total sentences in each category. 
Table 3 Relationship between reporters' vitamin D publication history and characteristics of articles on the Institute of Medicine (IOM) report Dietary Reference Intakes for Calcium and Vitamin D

\begin{tabular}{|c|c|c|c|c|c|c|}
\hline \multirow{2}{*}{$\begin{array}{l}\text { History of articles on } \\
\text { vitamin } D \text { benefits }\end{array}$} & \multirow[b]{2}{*}{$n$} & \multicolumn{2}{|c|}{$\begin{array}{l}\text { Proportion of sentences } \\
\text { focused on IOM ('IOM') }\end{array}$} & \multicolumn{2}{|c|}{$\begin{array}{l}\text { Proportion of sentences focused on } \\
\text { criticism of IOM ('criticism') }\end{array}$} & \multirow{2}{*}{$\begin{array}{l}\text { Reported risks of excess intake on } \\
\text { kidney and heart (yes:no) }\end{array}$} \\
\hline & & Mean & SD & Mean & SD & \\
\hline Yes & 5 & 0.412 & 0.060 & $0 \cdot 264$ & 0.069 & $1: 4$ \\
\hline & 5 & 0.424 & 0.113 & 0.102 & 0.077 & 4:1 \\
\hline$P$ value & & \multicolumn{2}{|c|}{$0.841^{*}$} & \multicolumn{2}{|c|}{$0.008^{\star}$} & $0.058 t$ \\
\hline
\end{tabular}

'Non-vitamin D' sentences excluded from proportion of total sentences in calculation of mean proportion of sentences focused on IOM and criticism of IOM. ${ }^{*} P$ value for two-tailed $t$ test.

$+P$ value for Pearson's $\chi^{2}$ test.

reporters with no pre-report history of articles about vitamin $\mathrm{D}$ benefits $(P<0 \cdot 01$, Table 3$)$. In four of the five articles by authors with pre-report articles, one or more of the IOM critics mentioned had been cited in one or more prior vitamin $\mathrm{D}$ articles by the same author. No significant difference was found between pre-report articles on vitamin $\mathrm{D}$ benefits and the percentage of sentences focused on the IOM recommendations ( $P=0 \cdot 841$, Table 3$)$. Twenty per cent of reporters who wrote pre-report articles on vitamin D benefits, compared with $80 \%$ with no such history, included text on the risk of excessive vitamin $\mathrm{D}$ intake $(P=0 \cdot 058$, Table 3$)$.

\section{Discussion}

The IOM report Dietary Reference Intakes for Calcium and Vitamin $D$ attracted controversy, particularly around the new RDA for vitamin D, which some critics considered too low ${ }^{(22,23)}$. The report cast doubt on the strength of evidence supporting suggestions in the popular press of widespread vitamin D deficiency in North Americans and potential benefits of supplementation beyond the revised recommendations.

Of the top thirty US and top three English-language Canadian newspapers, most did not include coverage of the IOM report, suggesting that the report did not receive a level of coverage commensurate with the apparent interest in vitamin $\mathrm{D}$ as assessed on the basis of serum screening frequency and supplement sales $^{(11,12)}$. The articles that met our inclusion/exclusion criteria contained relatively consistent information for the revised RDA value for young and middle-aged adults. However, risk factors for deficiency were not included in $40 \%$ of articles. In addition, $30 \%$ of articles did not indicate that there was a Tolerable Upper Intake Level for vitamin D and $50 \%$ of the articles did not report on the consequences of excess vitamin D intake. These data raise questions about whether critical information that could have benefited subgroups of the population or the population as a whole was consistently communicated.

Among the articles assessed, the proportion of sentences critical of the IOM report varied from $4 \%$ to $35 \%$.
Thus, readers of different newspapers may have perceived different levels of contentiousness in the scientific community around the revised IOM recommendations. Further, comparing pre-report and post-report articles written by individual reporters suggested that differences among newspaper articles may have been related to reporters' preconceived ideas. Reporters having written pre-report articles highlighting the benefits of vitamin D dedicated a significantly greater proportion of sentences in their post-report articles to criticizing the IOM report and were less likely to report potential adverse effects of excess intakes. In several cases, critical viewpoints expressed in IOM articles were attributed to experts whom the authors had cited in previous articles. One explanation for these trends is that authors' prior consultation with these experts skewed how they evaluated and reported information on the IOM report. Given that the public relies heavily on the news media to obtain objective translation of dietary recommendations, these findings are of concern.

The findings of the present study may reflect the shifting landscape of science news reporting. In a recent survey of the Association of Health Care Journalists, over half of respondents indicated that the amount of time they had to prepare stories has declined in recent years, $88 \%$ indicated an increased emphasis on 'quick hit' stories and $94 \%$ suggested that cost pressures have compromised the quality of health news reporting ${ }^{(31)}$. A survey of Midwestern daily newspapers reporters found $83 \%$ of respondents had no training to cover health topics ${ }^{(32)}$. These data suggest the need for the public health nutrition community to proactively engage with mainstream media to ensure that health-related recommendations, particularly revised recommendations, are reported clearly and completely from an unbiased perspective. This may require the use of experts who are not personally invested in the subject at hand. A recent study found that in reviewing meta-analysis findings, authors whose studies were included in the analysis, and who had reported significant results, were more likely than independent methodologists to interpret the findings as representing a strong association ${ }^{(33)}$. Similarly, in the present case, the involvement of vitamin D experts with 
investment in the field may have skewed reporting on the IOM's report.

While the present analysis provides evidence of variability in documenting the key points of the IOM report, it has limitations. The sample included only ten articles, all drawn from US and Canadian print newspapers with the highest circulation, so our analysis has limited generalizability and our findings may not be externally valid for other types of news media. However, the top four US and top two Canadian newspapers are represented in the articles in our sample; articles with such wide reach are likely to be particularly influential in terms of public perceptions and influence the content of other media outlets. To avoid potentially contaminating data extraction and analysis with personal interpretation, methodologies were used that incorporated previously published standards, objective assessment techniques (e.g. grammatical sentence mapping) and multiple independent coders. However, our analysis could not directly assess other aspects of reporting, such as the ordering of concepts within an article. Reporters who wrote pre-report articles may have been science writers or have had more of a background in the area than reporters without such a history. We were unable to assess such background from available information or determine whether that variable would have a significant impact on the content of their articles. Likewise, we could not determine the impact of the newspaper editorial staff on the final article content.

\section{Conclusion}

The present study shows that the majority of major North American newspapers, defined based on total circulation, did not cover the release of the IOM Dietary Reference Intakes for Calcium and Vitamin D report and that the newspapers that did publish articles on the topic meeting the inclusion/exclusion criteria varied in terms of both the specific findings reported and the relative emphasis given to key points of the report. It also suggests that some of the variability in newspaper article content was associated with the reporters' pre-report publication histories on vitamin $D$. In addition to analysis and interpretation by the reporter, reporting of nutrition topics would benefit from the development of content standards that ensure comprehensive coverage of the topic.

\section{Acknowledgements}

Sources of funding: This research received no specific grant from any funding agency in the public, commercial or not-for-profit sectors. Conflicts of interest: The authors have no conflicts of interest to report. Ethics: Ethical approval was not required. Authors' contributions: D.P.H. and K.P.S. contributed equally to the study. D.P.H., K.P.S., J.L. and A.H.L. designed the project; D.P.H. and K.P.S. collected and analysed the data; D.P.H., K.P.S. and A.H.L. drafted the manuscript; D.P.H., K.P.S., A.H.L. and J.L. reviewed and modified the manuscript.

\section{References}

1. The Henry J. Kaiser Family Foundation (2005) Public Opinion Snapshot on Health Information Sources - July 2005. http://kff.org/other/poll-finding/public-opinion-snapshot-onhealth-information-sources/

2. McIntosh J \& Blalock SJ (2005) Effects of media coverage of Women's Health Initiative study on attitudes and behavior of women receiving hormone replacement therapy. $A m \mathrm{~J}$ Health Syst Pharm 62, 69-74.

3. Grilli R, Ramsay C \& Minozzi S (2002) Mass media interventions: effects on health services utilisation. Cochrane Database Syst Rev issue 1, CD000389.

4. Roberts M, Wanta W \& Tzong-Horng D (2002) Agenda setting and issue salience online. Commun Res 29, 452-465.

5. Henderson L, Kitzinger J \& Green J (2000) Representing infant feeding: content analysis of British media portrayals of bottle feeding and breast feeding. BMJ 321, 1196-1198.

6. Philo G, Secker J, Platt S et al. (1994) The impact of the mass media on public images of mental illness: media content and audience belief. Health Educ J 53, 271-281.

7. Stryker JE (2002) Reporting medical information: effects of press releases and newsworthiness on medical journal articles' visibility in the news media. Prev Med 35, 519-530.

8. Schwitzer G (2008) How do US journalists cover treatments, tests, products, and procedures? An evaluation of 500 stories. PLoS Med 5, e95.

9. Basu AJ \& Hogard E (2008) Fit for public consumption? An exploratory study of the reporting of nutrition research in UK tabloids with regard to its accuracy, and a preliminary investigation of public attitudes towards it. Public Health Nutr 11, 1124-1131.

10. Keenan DP, AbuSabha R \& Robinson NG (2001) Content analysis of media coverage of the 1995 dietary guidelines for Americans. J Extension 39, issue 5; available at http:// www.joe.org/joe/2001october/rb5.php

11. Quest Diagnostics (2010) 2009 Annual Report. http://media. corporate-ir.net/media_files/irol/82/82068/2009AR/quest_ packaged_final/quest_packaged_final/downloads/ar_2009.pdf

12. Beck M (2010) Triple that vitamin D intake, panel prescribes. The Wall Street Journal, 30 November 2010, p. D:1.

13. Institute of Medicine (1997) Dietary Reference Intakes for Calcium, Phosphorus, Magnesium, Vitamin D and Fluoride. Washington, DC: National Academy of Sciences.

14. Institute of Medicine (2010) Report Brief: Dietary Reference Intakes for Calcium and Vitamin D. http://www.iom.edu/ Reports/2010/Dietary-Reference-Intakes-for-Calcium-andVitamin-D/Report-Brief.aspx

15. Institute of Medicine (2011) Dietary Reference Intakes for Calcium and Vitamin D. Washington, DC: The National Academies Press.

16. Ross AC, Manson JE, Abrams SA et al. (2011) The 2011 Dietary Reference Intakes for Calcium and Vitamin D: what dietetics practitioners need to know. J Am Diet Assoc 111, 524-527.

17. Rosen CJ (2011) Clinical practice. Vitamin D insufficiency. $N$ Engl J Med 364, 248-254.

18. Manson JE, Mayne ST \& Clinton SK (2011) Vitamin D and prevention of cancer - ready for prime time? $N$ Engl J Med 364, 1385-1387.

19. Shapses SA \& Manson JE (2011) Vitamin D and prevention of cardiovascular disease and diabetes: why the evidence falls short. JAMA 305, 2565-2566. 
20. Ross AC (2011) The 2011 report on dietary reference intakes for calcium and vitamin D. Public Health Nutr 14, 938-939.

21. Song Y, Manson JE \& Liu S (2011) Response to Mascitelli et al. 'Chronic lung diseases, diabetes and hypovitaminosis D: is there a connection?' Diabetes Res Clin Pract 92, e55-e56.

22. Heaney RP \& Holick MF (2011) Why the IOM recommendations for vitamin D are deficient. J Bone Miner Res 26, 455-457.

23. Holick MF (2011) The D-batable Institute of Medicine report: a D-lightful perspective. Endocr Pract 17, 143-149.

24. Alliance for Audited Media (not dated) Top 25 US Newspapers for September 2010. http://auditedmedia.com/news/ research-and-data/top-25-us-newspapers-for-september-2010. aspx

25. Canadian Newspaper Association (2010) Circulation data report 2009. http://www.newspaperscanada.ca/sites/default/ files/2009CirculationDataReport.pdf

26. International Food Information Council Foundation \& Institute of Food Technologists (2005) Guidelines for Communicating the Emerging Science of Dietary Components for Health. For Journalists, Health Professionals, and other Communicators. http://www.foodinsight.org/Content/ 6/FFGuidelnsBro.pdf

27. Wansink B (2006) Position of the American Dietetic Association: food and nutrition misinformation. J Am Diet Assoc 106, 601-607.

28. Schwitzer G (2004) A statement of principles for health care journalists. Am J Bioethics 4, W9-W13.

29. Hall J (2010) Panel triples sunshine vitamin quota; The good news: Most of us already get enough vitamin D through diet alone, report says. The Toronto Star, 1 December 2010, p. E:9.

30. Stein R (2010) Go slow on vitamin D supplements. The Washington Post, 7 December 2010, p. E:5.
31. Schwitzer G (2009) The State of Health Journalism in the United States. Menlo Park, CA: The Henry J. Kaiser Family Foundation; available at http://kaiserfamilyfoundation. files.wordpress.com/2013/01/7858.pdf

32. Voss M (2002) Checking the pulse: Midwestern reporters' opinions on their ability to report health care news. $A m J$ Public Health 92, 1158-1160.

33. Panagiotou OA \& Ioannidis JP (2012) Primary study authors of significant studies are more likely to believe that a strong association exists in a heterogeneous metaanalysis compared with methodologists. J Clin Epidemiol 65, 740-747.

34. Kolata G (2010) Extra vitamin D and calcium aren't necessary, report says. The New York Times, 30 November 2010, p. A:1.

35. Sapatkin D (2010) Panel triples vitamin D intake guideline. The Philadelphia Inquirer, 30 November 2010, p. A:1.

36. Mittelstaedt M (2010) Vitamin D panel triples recommended dose to $600 \mathrm{IU}$; Cancer-prevention claims need blind trials, researchers say. The Globe and Mail, 30 November 2010, p. L:1.

37. Lazar K (2010) Calcium, Vitamin D changes suggested; But flaws are seen in long-awaited report. The Boston Globe, 30 November 2010, p. B:5.

38. Hellmich N (2010) Got calcium? Probably enough, report says. USA Today, 30 November 2010, p. A:3.

39. Healy M (2010) Americans get enough calcium and vitamin $\mathrm{D}$, panel concludes; For all but a few, boosting intake is seen as useless and possibly harmful. Studies on the benefits are called 'contradictory'. The Los Angeles Times, 1 December 2010, p. A:11.

40. Weintraub K (2010) Experts disagree about how much vitamin D and calcium you should get. The Boston Globe, 20 December 2010, p. G:13. 